\title{
Development of the Information Management System for Monitoring Alien Invasive Species
}

\author{
Hui $\mathrm{Li}^{1}$, Ningning $\mathrm{Ge}^{1}$, Lingwang Gao ${ }^{1, *}$, Zuorui Shen ${ }^{1}$, Guoliang Zhang ${ }^{2}$, \\ Zhiyuan $\mathrm{Zang}^{3}$, and ${\mathrm{Yi} \mathrm{Li}^{3}}^{3}$ \\ ${ }^{1}$ IPMist Lab, College of Agriculture and Biotechnology, China Agricultural University, \\ Beijing, P.R. China, 100193 \\ Tel.: +86-10-62731884 \\ lwgao@cau.edu.cn \\ ${ }^{2}$ Institute of environment and sustainable development in agriculture, The Chinese Academy of \\ Agricultural Sciences (CAAS), Beijing, P.R. China, 100081 \\ ${ }^{3}$ Beijing Candid soft Technology Co. Ltd. Beijing, P.R. China, 100083
}

\begin{abstract}
One of the effective methods to prevent the excessive extending of alien invasive species is to really master their epidemic trends and to take appropriate measures to control them. So, the information management system for monitoring alien invasive species based on the integrated technology was developed to provide the information services for the governments, experts and farmers. The main modules of the system are the sub-system of investigation data management and the sub-system of real-time epidemic reporting in new extending area. In the investigation data management sub-system, the dynamic data of the invasive species in invaded areas can be input into the system. And in the sub-system of real-time epidemic reporting in new extending area, the epidemic information can be reported in E-mail, telephone-voice, short message, voice mail, videoconference or other format with users' telephone, cell phone, personal computer, and personal digital assistant(PDA) based on the integrated technology. The system built the information exchanging bridges among the governments, experts and farmers, letting them to make more effective decisions.
\end{abstract}

Keywords: the alien invasive species, the epidemic situation, multipath report, integrated technology.

\section{Introduction}

At present, the situation of alien invasive species is very serious in China. The whole country except Tibetan plateau in remote areas has been threaten or been effected by the alien invasive species in variant degrees [1]. Cattau's study highlights the implications of conservation of native species and also describes the importance of effects that invading species have on the native species, especially those that are endangered, because the subtle influences on behavior may have an important significance on population density [2]. Pine wood nematode had extended into Jiangsu, Zhejiang, Anhui, Shandong and Guangdong in 1999, making 15 million trees cumulatively die [3].

${ }^{*}$ Corresponding author.

D. Li, Y. Liu, and Y. Chen (Eds.): CCTA 2010, Part I, IFIP AICT 344, pp. 594 599. 2011.

(C) IFIP International Federation for Information Processing 2011 
Till present a lot of research has been done. Darren's research on the interactions between a biological control agent (Cleopus japonicas) and its plant host (Buddleja davidii). It is based on a mess of data, which are precise and reliable and successive three years' data from 2007 to 2009[4]. And some risk assessment models are introduced for preventing alien invasive species. But the reliability of the total risk score clearly depends on the quality of the available data and the experience of the assessor.

The key principle of international environment law is to prevent the risks and harms before the insertion of the alien invasive species [4]. The exact investigation data will help people put the theoretical principle into the factual effect. And they directly influence the macro decision of the harmful biological control [5].

With the rapid development of the computer and information technology, the agriculture in China gets an opportunity of rapid progress. On the fields of agricultural production and management, computers, as a resource, take a prominent role by its high speed and large storage, retrieval convenience and quick transmission of information [6]. From a Japanese report about the computer's application on the alien invasive species, because of their potentially wide spatial coverage, an integrated information system that presents their epidemic situation needs to be developed [7]. In addition, the integrated technology mixes sensors, computers, and communication devices and unceasingly change the ways of precision agriculture [8].

In this paper, the development of the information management system for monitoring alien invasive species based on the integrated technology was reported. The system can provide information services for the governments, experts and farmers with the data of occurrence and dissemination of the alien species and set an entire set of information interaction in them.

\section{Designing of the System}

\subsection{Environment for the System Development}

The system was developed with PHP5.0 based on the Microsoft Windows XP Professional Service Pack 2 on PC with Intel(R) Pentium(R) 4 CPU3.00GHz, 1.25G EMS, and 120G HD. MySQL DBMS was employed to provide the support of the data management in the system. The system can be run on Microsoft Windows 2000/XP/2003 and Linux, etc.

\subsection{Structure of the System}

The platform consists of six main parts by now: (1) The sub-system of investigation data management; (2) The sub-system of real-time epidemic reporting in new extending area; (3) The sub-system of monitoring data acquisition and management; (4) The sub-system of expert response based on the internet and telecommunications networks; (5) The sub-system of management system of literature; (6) The sub-system of administration of experts. This passage mainly introduces the first two parts. 


\subsection{The Sun-System of Investigation Data Management}

In order to meet the need of scientific research and preventive practice, a lot of epidemic data will be put into the multifunctional platform by professional workers in this field. The epidemic data are mainly divided into three parts. The first part includes the natural information (for example, the area in which the alien invasive species has occurred.); the second part are about the agricultural information, including crops and their details; and the last one is the fugacious data-the epidemic information, that is, the occurrence and hazard information of the alien species (Fig. 1). The system provides investigators the access to inputting the data and recording the information of them. So, each datum can cast back to a single recorder insuring the reliability and veracity of the data in the system.

In addition, the environmental data (including the air temperature, air humidity, soil temperature, soil humidity, etc.) is recorded with automation recorder and transmitted to database in the system.

\subsection{The Sub-system of Real-Time Epidemic Reporting in New Extending Area}

When new extending area of the alien invasive species is found, the information can be easily concentrated on the platform by sending short messages, calling phone or using Internet and stored to a stable database in the system. After the reporting information into the platform, the system would send the information to the related departments and experts automatically, and the information would be verified by professionals.

行政村黄顶菊调查表

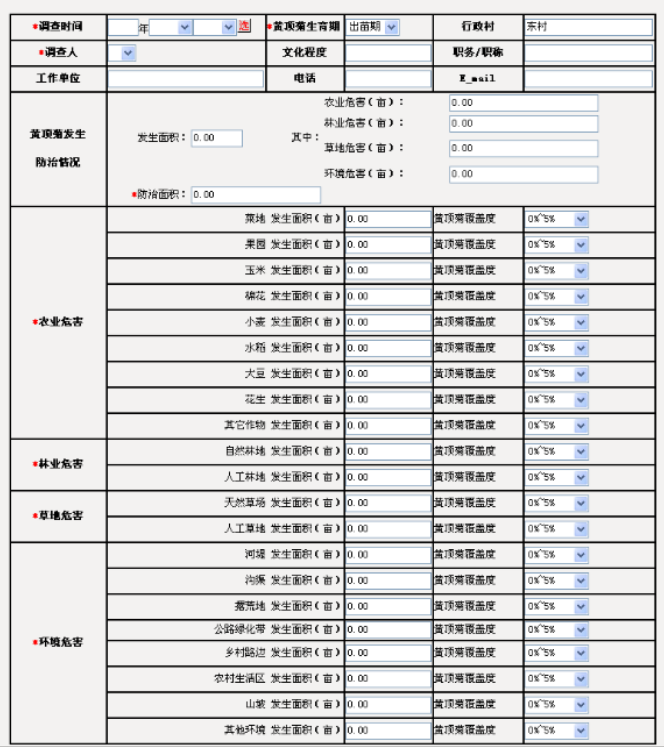

Fig. 1. The last part- the epidemic information

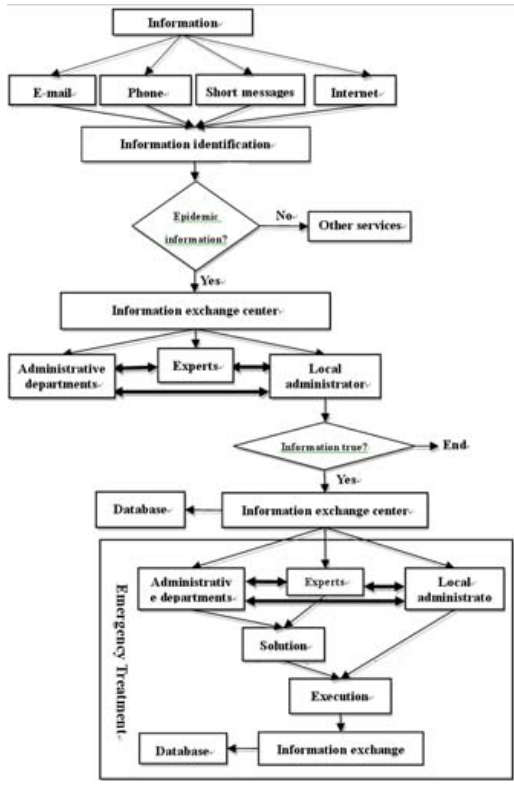

Fig. 2. The flow chart of epidemic information reporting 
If it is confirmed as a piece of valid new epidemic information, the administrative departments, experts, and local departments would hold a consultation meeting to discuss the emergency and develop specific implementation plans. Emergency measures would be started up. The detailed process is as fig2. So this sub-system saves more reporting time from finder to decision maker than paper file reporting. It is quite significant that any person can access to the platform in time no matter who are you and where are you.

\section{Discussion}

\subsection{The Superiority of the Platform}

Till now a lot of researches have largely been referred to plant physiology, plant ecology, biology and some prediction modules including the dynamic population of alien invasive species $[9,10,11]$. But all researches will be based on abundant reliable data. This is also the fetter of promoting recent research. And any ecological systems are often very complicated involving non-linear responses to environmental factors and involving density-dependent processes. And every of the alien invasive species might have wide potential suitable areas in China. For example Flaveria bidentis, a new exotic invasive plant originating from South America [12]. The potential extended areas of it in China, which are estimated by using the CLIMEX software, would contain Guangdong, Guangxi, Yunnan, Hainan, Fujian, Taiwan, Jiangxi, Hunan, Guizhou, Sichuan, Chongqing, Hubei, Anhui, Jiangsu, and Shanghai provinces. Among these, Guangdong, Guangxi, Taiwan, Hainan, Fujian, Yunnan, Sichuan, Guizhou, Chongqing and part of Xizang are at the high risk [13]. But it is obvious that getting dynamic data of the alien invasive species is an enormous, intricate and lengthy project. So the superiority of the platform lies in inputting and saving dynamic information by computer and web.

In addition, the multipath information report in the platform, which integrates the internet, mobile and fixed-line telephone, is very convenient especially for farmers in rural regions to report the extending situation. No matter which is chosen, the extending information can be stored in a database and be timely transmitted to related government departments and experts. This would change the situation that most efficiency information in the rural and remote regions cannot be timely transmitted to related departments. And it also resolves this problem that the alien invasive species, in broad china area, could be hard timely discovered [14] by widening channels of information (mobile, fix-phone and internet) to the related departments and by arousing the broad masses.

And by means of these interactive methods the government departments are able to give some instructive and legal advice to the farmers and experts in this region. Simultaneously experts also can provide some actual preventative measures through their decision-making according to the physiological property of alien species and the natural conditions of this region. This platform becomes an orderly high-speed information cyclic system, which breaks the limitation of geographical space and which simplifies the procedure of the information report. 


\subsection{The Development of the Platform}

Remote Sensing, Geographical Information System and Global Positioning System (3S) would be introduced into the platform which can make epidemic data richer and more precise. $3 \mathrm{~S}$ technology has been broadly applied in agricultural data inquiry. For example, the inquiry of slop soil distribution in indifferent slop grades [15].

And even if farmers' and researchers' hard drives have filled up with images, maps and data-filled spreadsheets, we are drowning in information. So we need to accelerate the process from collecting information into making reliable decisions [8]. It is necessary to add a forecasting support system, an identification system and an expert decision-making system to the integrated platform, such as a forecasting decision support system [16], the expert system platform for forecast and prediction of agricultural pests [17], and a management system for rice leaf roller [18].

If this platform can be associated with the related webs, for example, the national quarantine web and the national agricultural web, it would be more advantageous to government departments, experts, investigators, and formers. More full information, more sagacious decisions.

\section{Acknowledgments}

This research was supported by Public Welfare Project from Ministry of Agriculture of the People's Republic of China (Grant No: 200803022 and 200803006).

\section{References}

[1] Cai, L., Yu, Z., Wang, J., Wang, D.: Control Alien Invasive Species to Conserve Biodiversity. J. Environmental Protection (08), 27-34 (2003)

[2] Cattau, C.E., Martin, J., Kitchens, W.M.: Effects of an exotic prey species on a native specialist: example of the snail kite. J. Biological Conservation 143(2), 513-520 (2010)

[3] Zhang, R., Zhang, D., Ye, W., Sang, W., Xue, D., Li, W.: Research Progress and Prospects of Invasive Alien Species. J. Plant Protection 30(3), 5-9 (2004)

[4] Kriticos, D.J., Watt, M.S., Withers, T.M., Leriche, A., Watson, M.C.: A process-based population dynamics model to explore target and non-target impacts of a biological control agent. J. Ecological Modelling (220), 2035-2050 (2009)

[5] Xing, A.: Principle of International Law and Its Implementing to Prevent Alien Invasive Species. J. Ecological Economy (12), 26-35 (2006)

[6] Qiang, B.: The application prospect of computer-centered information technology on agriculture. J. Computer and Agriculture (2), 1-3 (2001)

[7] Kitamoto, A., Nakahara, M., Washitani, I., Kadoya, T., Yasukawa, M., Kitsuregawa, M.: Information visualization and organization for participatory monitoring of invasive alien species. In: 20th International Workshop on Database and Expert Systems Applications, pp. 345-349. Institute of Electrical and Electronics Engineers Inc., New York (2009)

[8] Kitchen, N.R.: Emerging technologies for real-time and integrated agriculture decisions. J. Computers and Electronics in Agriculture 61(1), 1-3 (2008) 
[9] Bartomeus, I., Vilà, M., Steffan-Dewenter, I.: Combined effects of Impatiens glandulifera invasion and landscape structure on native plant pollination. J. Journal of Ecology 98(2), 440-450 (2010)

[10] Smolik, M.G., Dullinger, S., Essl, F., Kleinbauer, I., Leitner, M., Peterseil, J., Stadler, L.M., Vogl, G.: Integrating species distribution models and interacting particle systems to predict the spread of an invasive alien plant. J. Journal of Biogeography 37(3), 411-422 (2010)

[11] Stanisci, A., Acosta, A.T.R., Di Iorio, A., Vergalito, M.: Leaf and root trait variability of alien and native species along Adriatic coastal dunes (Italy). J. Plant Biosystems 144(1), 47-52 (2010)

[12] Powell, A.M.: Systematics of Flaveria (F1averimae, Asteraceae). J. Annals of the Missouri Botanical Garden (65), 590-636 (1978)

[13] Bai, Y., Cao, X., Chen, C., Hu, B., Liu, F.: Potential distribution areas of alien invasive plant Flaveria bidentis (Asteraceae) in China. J. Journal of Applied Ecology 20(10), 2377-2383 (2009)

[14] Fang, Z., Lu, Y., Wu, Y.: The discussion about investigating the agriculture pest. J. Plant Quarantine 20(3), 185-186 (2006)

[15] Su, G.: The Inquiry of Slop Soil Distribution in Indifferent Slop Grade Based on '3S'. J. Journal of Guangxi College of Education (5), 63-65 (2007)

[16] Wu, F., Hua, T.: Design and Implementation of a Forecasting Decision Support System. J. Journal Harbin UNIV 3(6), 63-65 (1998)

[17] Gao, L., Chen, J., Yu, X., Wang, C., Bu, B.: Research and development of the expert system platform for forecast and prediction of agricultural pests. J. Transactions of the CSAE 22(10), 154-158 (2006)

[18] Hu, Q., Xu, R., Wang, Y., Huang, Y., Yu, Z.: A Management System for Rice Leaf Roller. J. Journal of Anhui Agricultural College 18(3), 227-233 (1991) 